\title{
Carbon cloth-based immunosensor for detection of 25-hydroxy vitamin $\mathrm{D}_{3}$
}

\author{
Deepika Chauhan ${ }^{1} \cdot$ Amit K. Yadav ${ }^{1} \cdot$ Pratima R. Solanki $^{1}$ (I) \\ Received: 23 November 2020 / Accepted: 8 February 2021 / Published online: 1 April 2021 \\ (C) The Author(s), under exclusive licence to Springer-Verlag GmbH Austria, part of Springer Nature 2021
}

\begin{abstract}
Vitamin D (VD) deficiency is a global health concern due to its serious health impacts, and at present, the monitoring of VD status is expensive. Here, a novel immunosensor for sensitive and label-free detection of 25 -hydroxy vitamin $\mathrm{D}_{3}\left(25 \mathrm{VD}_{3}\right)$ is reported. Nanostructured cerium(IV) oxide $\left(\mathrm{nCeO}_{2}\right)$ was anchored onto carbon cloth $(\mathrm{CC})$ via electrophoretic deposition to fabricate a nanoplatform $\left(\mathrm{nCeO}_{2} / \mathrm{CC}\right.$ ). Subsequently, bioactive molecules (anti-25 $\mathrm{VD}_{3}$ and $\mathrm{BSA}$ ) were introduced to fabricate the nanobioplatform $\mathrm{BSA} / \mathrm{anti}-25 \mathrm{VD}_{3} / \mathrm{nCeO}_{2} / \mathrm{CC}$ as an immunosensor. The analytical performance of the developed immunosensor was studied towards $25 \mathrm{VD}_{3}$ detection. The immunosensor provides a broad linear range of 1-200 $\mathrm{ng} \mathrm{mL} L^{-1}$, high sensitivity of $2.08 \mu \mathrm{A} \mathrm{ng}^{-1} \mathrm{~mL} \mathrm{~cm}^{-2}$, a detection limit of $4.63 \mathrm{ng} \mathrm{mL}^{-1}$, and a response time of $15 \mathrm{~min}$, which is better than that of previous reports. The biosensor exhibited high selectivity, good reproducibility, and excellent stability for about 45 days. The potential application of the proposed immunosensor was observed for real serum samples towards $25 \mathrm{VD}_{3}$ detection that demonstrated a high correlation with the conventional enzyme-linked immunosorbent assay.
\end{abstract}

Keywords Carbon cloth $\cdot$ Nanostructured ceria $\cdot$ Immunosensor $\cdot 25$-Hydroxy vitamin $\mathrm{D}_{3} \cdot$ Serum sample

\section{Introduction}

Vitamin D (VD) deficiency is a global health concern due to its serious health impacts including bone disorder, cardiovascular diseases, infections, diabetes, osteoarthritis, tuberculosis, hypertension, and even cancer. Besides this, there are many other physiological functions in which VD endocrine system helps to modulate and they have a direct relation with VD, viz immune response, regulation of cell proliferation, and differentiation [1,2]. Recently, scientists have also correlated VD deficiency with the COVID-19 cases. Various reports showed a correlation between VD deficiency and risk of COVID-19. The study also showed that peoples having lower VD level developed more inflammatory markers (ferritin and D-dimer) that are linked to poor COVID-19 outcomes. It has been reported that VD might be helpful to prevent "cytokine storms" seen in few COVID-19 patients by attenuating the immune system response. Also, supplementation of $\mathrm{VD}_{3}$ could be a

Pratima R. Solanki

pratimarsolanki@gmail.com; partima@mail.jnu.ac.in

1 Special Centre for Nanoscience, Jawaharlal Nehru University, New Delhi 110067, India promising approach to reduce the risk of COVID-19 [weblink 1 , weblink 2, weblink 3, and weblink 4]. VD is available in two major forms, namely $\mathrm{VD}_{2}$ and $\mathrm{VD}_{3}$, and the available research reports suggest the preferable form is $\mathrm{VD}_{3}$ over $\mathrm{VD}_{2}$. Further, out of all the available analytical forms of $\mathrm{VD}_{3}$, clinical research considered 25-hydroxy vitamin $\mathrm{D}_{3}$ $\left(25 \mathrm{VD}_{3}\right)$ as the best parameter to indicate VD status. It is due to the reason that $25 \mathrm{VD}_{3}$ has a much higher serum concentration $(\sim 99 \%)$ and a longer half-life (about 3 weeks) and is therefore measured mainly during the VD test in clinical diagnosis [3]. Therefore, human plasma/serum $25 \mathrm{VD}_{3}$ is widely used as a biomarker $[4,5]$. The standard physiological range of VD is $30-70 \mathrm{ng} \mathrm{mL}^{-1}$ and a value below $30 \mathrm{ng} \mathrm{mL}^{-1}$ indicates an alarming situation of VD deficiency. Hence, timely assessment of VD levels in body fluid can avoid nutritional deficiencies and also prevents irreversible damage caused to vital organs.

Currently, the analysis methods adopted for VD monitoring are liquid chromatography-mass spectrometry (LC-MS), radioimmunoassay (RIA), high-performance liquid chromatography (HPLC), and enzyme-linked immunoassays (ELISA) [6]. Although HPLC and ELISA can be routinely performed by trained technicians still these methods have some limitations. In HPLC, large quantities of expensive 
organics are required that increases the cost of analysis. Also, HPLC have low sensitivity for certain compounds, and some cannot be detected as they are irreversibly adsorbed. In the case of ELISA, a format consisting of a 96-well plate is used and it requires $100-200 \mu \mathrm{L}$ of sample for each well during testing. Such a large demand for sample volume will hinder how many targets can be quantified from the test sample and severely limit the ability to add replicates for more accurate, reliable results. The possibility of false-positive or negative results is high in ELISA due to insufficient blocking of immobilized antigen [7]. Thus, there is an urgent need to fabricate a fast and cost-effective point of care (POC) device like an immunosensor to monitor VD levels. In order to minimize delays in diagnosis, POC are useful diagnostic alternatives, which is vital since delays or ineffective procedures can result in high casualties. Chip, carbon cloth, and paper-based biosensors were established for quick detection with the improvements of POC research. It provides several incentives to users such as being affordable, flexible, sensitive, specific, userfriendly, rapid, robust, equipment-free, and deliverable [8-10]. The result can be achieved rapidly and conveniently, allowing for quick decision-making, thus minimizing the risk of human-to-human transmission. Few reports are available in the literature for the development of VD biosensors including the previous work done in our lab for VD detection [4, 11-16]. However, the biosensor developed for $25 \mathrm{VD}_{3}$ is very limited as shown in Table 1. Ozbakir et al., reported the enzymemodified electrode-based electrochemical detection of $25 \mathrm{VD}_{3}$ in a range of $5-200 \mathrm{ng} \mathrm{mL}^{-1}$ [14]. The process for the synthesis of the enzyme was time-consuming and follows a long procedure to do the cloning followed by expression study, and purification of proteins. Further, Carlucci et al. detected $25 \mathrm{VD}_{3}$ through electrochemical and surface plasmon resonance (SPR) techniques utilizing screen-printed gold $(\mathrm{Au})$ electrode and sensitivity obtained as $0.020 \mu \mathrm{A} \mathrm{ng}^{-1} \mathrm{~mL} \mathrm{~cm}^{-2}$ and limit of detection (LOD) as $10 \mathrm{ng} \mathrm{mL}^{-1}$. However, the use of the Au electrode is costly, and also the SPR technique requires expertise to handle the instrument [15]. One recent report for $25 \mathrm{VD}_{3}$ detection by Kaur et al. utilized goldplatinum bimetallic nanoparticles coated 3-(aminopropyl)triethoxysilane (APTES) for immunosensor $\left(\mathrm{Ab}-25(\mathrm{OH}) \mathrm{D}_{3} / \mathrm{Glut} / \mathrm{Au}-\mathrm{Pt} / \mathrm{APTES}\right)$ to detect $25 \mathrm{VD}_{3}[16]$.
The main shortcomings of the previous reports are the lack of validation study through a conventional technique of ELISA and also the real samples were not analyzed to test the efficiency of the electrodes. Thus, there is a wide scope to fabricate $\mathrm{VD}_{3}$ biosensors by utilizing different nanomaterials on appropriate substrates to improve the biosensing parameters.

Metal oxide nanostructured ceria $\left(\mathrm{nCeO}_{2}\right)$ demonstrates exciting features, and many reports are available for the detection of various analytes including glucose, DNA, cholesterol, hydrogen peroxide, cancer biomarkers, food toxins, and pesticides [17-20] for biosensor applications. Due to its unique features including electrical conductivity, nominal swelling, high mechanical strength, wide bandgap $(3.4 \mathrm{eV})$, oxygen storage capacity, and ability to switch oxidation states $\left(\mathrm{Ce}^{3+} /\right.$ $\left.\mathrm{Ce}^{4+}\right)[19,20]$; it provides a suitable biosensing platform. Moreover, it is non-toxic, shows chemical inertness, high adsorption capability, high electron transfer kinetics, and high isoelectric point IEP (9.2) [18] which makes $\mathrm{nCeO}_{2}$ a promising material for conjugation of desired bioactive molecules on the electrode surface.

The incorporation of nanomaterials onto a suitable substrate provides a synergetic effect to accelerate signal transduction leading to high sensitivity [21,22]. Among other substrates, carbon-based substrate exhibits good electrocatalytic activity, fast electron transfer kinetics, non-fouling effects, biodegradable, biocompatible, and cost-effective [23, 24]. Carbon cloth $(\mathrm{CC})$ is a flexible textile material and has carbon filaments of $5-10 \mu \mathrm{m}$ in diameter. $\mathrm{CC}$ is different from other rigid substates like Iindium tin oxide (ITO), fluorine tin oxide (FTO), and glassy carbon electrode (GCE). The application of $\mathrm{CC}$ as an electrode substrate provides enhanced diffusion of electrolyte and more channels to transport ion rapidly from electrolyte to electrode material [25]. In addition, CC exhibited high conductivity, chemical stability, lightweight, low-cost material, and three-dimensional structures showing its great potential in the fabrication of electrochemical biosensor. Moreover, $\mathrm{CC}$ possess interesting characteristics such as faster adsorption due to larger surface area, good biocompatibility, a low barrier to mass transfer. This substrate is mainly reported for supercapacitor applications. But, Mahesh et al. [26] reported an electrochemical sensor for dopamine detection. They

Table 1 Summary of the biosensors developed for VD detection until now

\begin{tabular}{|c|c|c|c|c|c|}
\hline Electrode & Technique used & Range & LOD & Sensitivity & Ref \\
\hline Ab-25OHD/SPE/FMTAD & $\begin{array}{l}\text { SPR } \\
\text { DPV }\end{array}$ & $\begin{array}{l}5-50 \mu \mathrm{g} \mathrm{mL}^{-1} \\
20-200 \mathrm{ng} \mathrm{mL}^{-1}\end{array}$ & $\begin{array}{l}1000 \mathrm{ng} \mathrm{mL}^{-1} \\
10 \mathrm{ng} \mathrm{mL}^{-1}\end{array}$ & $\begin{array}{l}4.8 \mathrm{~m}^{\circ}{\mathrm{mL} \mu \mathrm{g}^{-1}}^{-1} \\
0.020 \mu \mathrm{A} \mathrm{ng}^{-1} \mathrm{~mL} \mathrm{~cm}^{-2}\end{array}$ & {$[15]$} \\
\hline CYP27B1/GCE & $\mathrm{CV}$ & $5-200 \mathrm{ng} \mathrm{mL}^{-1}$ & - & - & [14] \\
\hline $\mathrm{BSA} / \mathrm{AB}-25 \mathrm{OHD}_{3} / \mathrm{CAEF} / \mathrm{RCP}$ & Chrono amperometry & $10-100 \mathrm{ng} \mathrm{mL}^{-1}$ & $10 \mathrm{ng} \mathrm{mL}^{-1}$ & $0.16 \mu \mathrm{A} \mathrm{ng}^{-1} \mathrm{~mL} \mathrm{~cm}{ }^{-2}$ & [4] \\
\hline $\mathrm{Ab}-25(\mathrm{OH}) \mathrm{D}_{3} / \mathrm{Glut} / \mathrm{Au}-\mathrm{Pt} / \mathrm{APTES}$ & DPV & $0.1-10^{6} \mathrm{pg} \mathrm{mL}^{-1}$ & $0.0049 \mathrm{ng} \mathrm{mL}^{-1}$ & - & {$[16]$} \\
\hline $\mathrm{BSA} /$ anti-25VD $3 / \mathrm{nCeO}_{2} / \mathrm{CC}$ & DPV & $1-200 \mathrm{ng} \mathrm{mL}^{-1}$ & $4.63 \mathrm{ng} \mathrm{mL}^{-1}$ & $2.08 \mu \mathrm{A} \mathrm{ng}^{-1} \mathrm{~mL} \mathrm{~cm}^{-2}$ & Present work \\
\hline
\end{tabular}


studied the catalytic activity of dopamine on iron oxide nanoparticles deposited on acid-treated CC. Therefore, CC substrate can be utilized for other electrochemical biosensor fabrication.

In this work, a simple electrochemical, label-free, standalone, and cost-effective immunosensor has been reported for $25 \mathrm{VD}_{3}$ detection based on $\mathrm{nCeO}_{2}$ anchored $\mathrm{CC}$. The $\mathrm{nCeO}_{2}$ was synthesized through the bottom-up approach and anchored to the CC substrate via electrophoretic deposition (EPD) to obtain the nanoplatform $\left(\mathrm{nCeO}_{2} / \mathrm{CC}\right)$. Subsequently, bioactive molecules like antibodies specific to $25 \mathrm{VD}_{3}$ (anti-25VD ) and bovine serum albumin (BSA) were immobilized on the nanoplatform for the development of nanobioplatform (BSA/ anti- $\left.25 \mathrm{VD}_{3} / \mathrm{nCeO}_{2} / \mathrm{CC}\right)$ as an immunosensor. The analytical performance of the developed immunosensor was observed and the results exhibited a better sensitivity, wide detection range, and good lowest detection limit in comparison to previously reported work for $25 \mathrm{VD}_{3}$ detection (Table 1). Moreover, the validation studies were also conducted using real samples and the results were found in good agreement with ELISA results.

\section{Experimental techniques}

\section{Chemicals and characterization techniques}

All the chemicals and reagents were of analytical grade and detailed information has been provided in the supplementary data. The detailed information of characterization techniques used for analysis is also given in the supplementary data.

\section{Synthesis of $\mathrm{nCeO}_{2}$ and fabrication of nanoplatform (nCeO $\mathrm{C}_{2} / \mathrm{CC}$ )}

$\mathrm{nCeO}_{2}$ was prepared by the bottom-up approach according to previous reports as mentioned in the supporting data [27, 28]. $\mathrm{CC}$ was utilized for the nanoplatform fabrication for which the surface of $\mathrm{CC}$ was pre-treated before the deposition of $\mathrm{nCeO}_{2}$. A large piece of $\mathrm{CC}$ was treated with a mixture of concentrated $\mathrm{H}_{2} \mathrm{SO}_{4}$ and $\mathrm{HNO}_{3}(1: 3)$ at $80{ }^{\circ} \mathrm{C}$ for $5 \mathrm{~h}$ followed by washing with de-ionized water (D.I. water) and ethanol several times and dried at $60{ }^{\circ} \mathrm{C}$ for $12 \mathrm{~h}$. This acid treatment promotes the activation of reactive functional groups available on $\mathrm{CC}$ [26]. After activation, desired dimensions $(0.5 \times$ $1.5 \mathrm{~cm}$ ) of $\mathrm{CC}$ were used for the deposition of $\mathrm{nCeO}_{2}$ using the EPD technique. For the EPD process, a suspension of $\mathrm{nCeO}_{2}\left(2 \mathrm{mg} \mathrm{mL}^{-1}\right)$ was prepared in IPA through sonication for $2 \mathrm{~h}$ at room temperature. EPD was carried out using a twoelectrode system in which CC (cathode) and a platinum wire (anode) were vertically oriented and separated by $1 \mathrm{~cm}$ in a container having a suspension of $\mathrm{nCeO}_{2}(4 \mathrm{~mL})$. A uniform and stable film $\left(\mathrm{nCeO}_{2} / \mathrm{CC}\right)$ was fabricated using an optimized parameter of $80 \mathrm{~V}$ potential for a duration of $3 \mathrm{~min}$. Further, the nanoplatform was rinsed with D.I. water to remove the excess material and then left for drying at $60{ }^{\circ} \mathrm{C}$ for $12 \mathrm{~h}$ to improve the binding. EPD is a versatile technique and has several advantages like short deposition time, simple apparatus requirement, and suitability for mass production and hence used for the deposition of $\mathrm{nCeO}_{2}$ onto CC. Also, EPD allows easy modifications as per the requirement of a specific application. For example, deposition can be performed on any type of substrate, viz flat, cylindrical, or any other shaped substrate with only minor changes in electrode design and positioning. Further, EPD offers easy control over the deposition thickness and morphology of deposited film by varying the deposition time and applied potential $[29,30]$. The fabricated nanoplatform was observed to check the flexibility and anchoring of $\mathrm{nCeO}_{2}$ onto $\mathrm{CC}$ (Supp data: Figure. S1).

\section{Fabrication of immunosensor through conjugation of bioactive molecules}

Initially, the stock solutions of anti-25VD 3 and BSA were made in PBS saline ( $\mathrm{pH} 7.0$ ) with a concentration of $1.15 \mathrm{mg} \mathrm{mL}^{-1}$ and $1 \mathrm{mg} \mathrm{mL}^{-1}$, respectively. Further, a final working dilution of anti-25VD $3\left(50 \mu \mathrm{g} \mathrm{mL}^{-1}\right)$ was made from the initial stock solution for further experiments. The effective conjugation of anti$25 \mathrm{VD}_{3}$ onto the surface of $\mathrm{nCeO}_{2} / \mathrm{CC}$ nanoplatform was done with the help of covalent binding using EDC-NHS chemistry. Solutions of anti-25 $\mathrm{VD}_{3}$, NHS $(0.1 \mathrm{M})$, and EDC $(0.4 \mathrm{M})$ were prepared by mixing them in a ratio of 2:1:1 (v/v) and kept for about 30 min at $4{ }^{\circ} \mathrm{C}$ resulting in activation of anti- $25 \mathrm{VD}_{3}$ carboxyl $\left(\mathrm{COO}^{-}\right)$groups. Thereafter, $20 \mu \mathrm{L}$ solution of activated anti-25 $\mathrm{VD}_{3}$ was drop cast onto $\mathrm{nCeO}_{2} / \mathrm{CC}$ nanoplatform and kept in a humid chamber for $6 \mathrm{~h}$ so that activated anti- $25 \mathrm{VD}_{3}$ binds effectively with $\mathrm{nCeO}_{2}$. This fabricated nanobioplatform anti- $25 \mathrm{VD}_{3} / \mathrm{nCeO}_{2} / \mathrm{CC}$ was washed with PBS for the removal of excess anti-25VD 3 from the surface. The blocking of nonbinding sites was done by introducing $10 \mu \mathrm{L}$ of BSA onto nanobioplatform (anti-25 $\mathrm{VD}_{3} / \mathrm{nCeO}_{2} / \mathrm{CC}$ ) and incubated for $4 \mathrm{~h}$. The obtained BSA/anti- $25 \mathrm{VD}_{3} / \mathrm{nCeO}_{2} / \mathrm{CC}$ nanobioplatform was washed with PBS and stored at $4{ }^{\circ} \mathrm{C}$ to maintain the activity of the immobilized bioactive molecules (BSA and anti-25VD 3 ). The stepwise fabrication process of the immunosensor is illustrated in Scheme 1.

\section{Results and discussions}

\section{Characterization of $\mathrm{nCeO}_{2}$}

To identify the crystallographic structure of $\mathrm{nCeO}_{2}, \mathrm{XRD}$ analysis was done and the XRD patterns (Fig. 1) showed eight well-resolved and intense peaks in the range of $2 \theta=10-80^{\circ}$. The diffraction peaks appeared at an angle $(2 \theta)$ were 28.56 , 


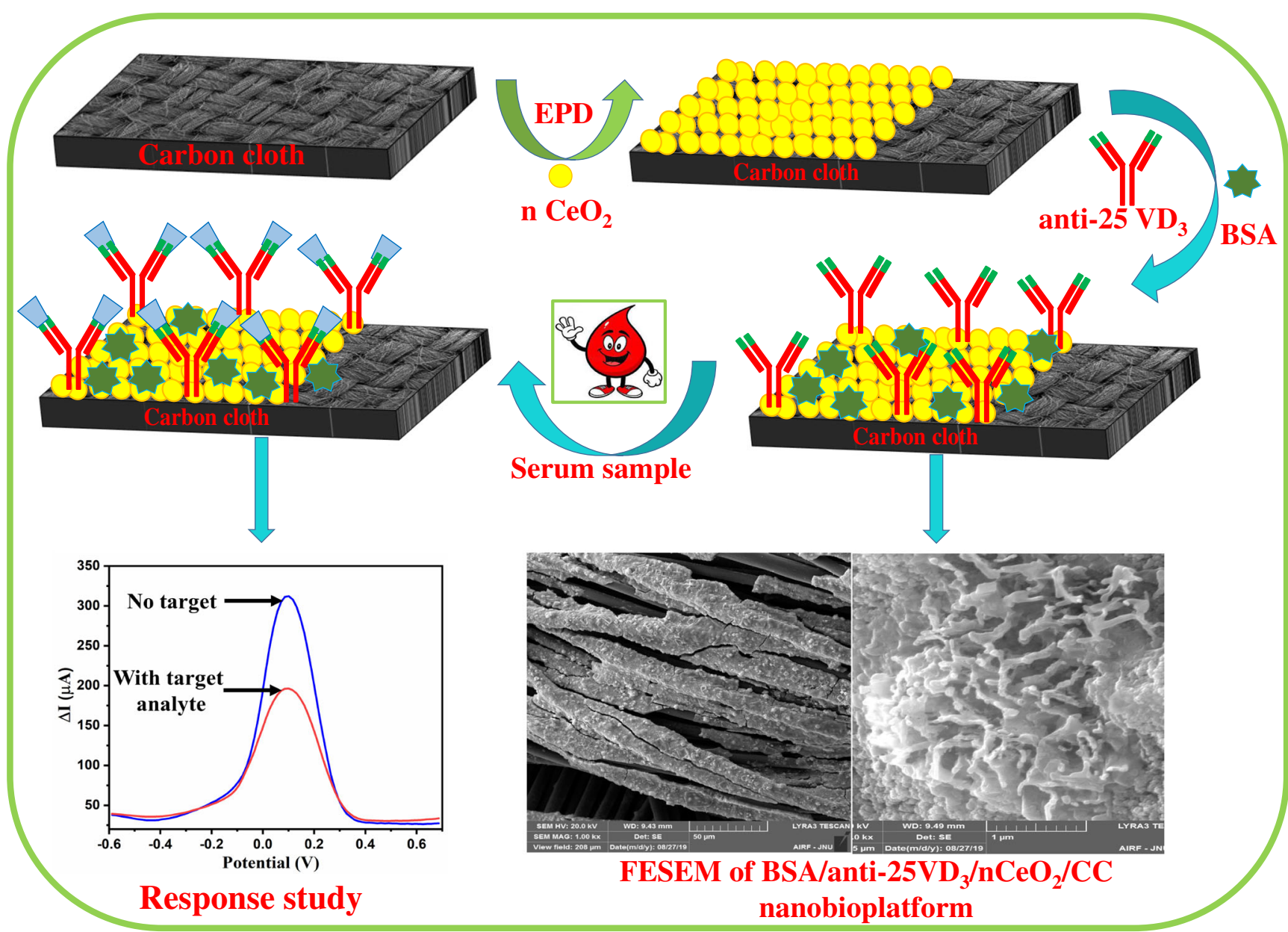

Scheme 1 Fabrication process of immunosensor BSA/anti-25VD $/ \mathrm{nCeO}_{2} / \mathrm{CC}$

$33.01,47.50,56.20,59.10,69.35,76.69$, and 78.99 which correspond to the crystal planes ascribed as (111), (200), (220), (311), (222) (400), (311), and (420), respectively [27, 31]. The XRD pattern demonstrated that all characteristic peaks are remarkably close to the face-centered-cubic (fcc) fluorite structure of $\mathrm{CeO}_{2}$ crystal (JCPDS: 34-0394). The fluorite structure consists of an arrangement where each cerium atom is surrounded by 8 oxygen atoms in an fcc arrangement and each oxygen atom has a cerium atom in a tetrahedron arrangement around it. No other peak was detected indicating the good crystallinity and preparation of $\mathrm{nCeO}_{2}$ in the pure phase.

The average crystallite size corresponds to the highest intensity peak (111) which was calculated using the Debye Scherer equation and found to be $10.35 \mathrm{~nm}$. The formula used for the calculation is as below:

$D=K \lambda / \beta \cos \theta$

where $K$ is the Scherer constant having a value in the range of 0.9 to $1, \beta$ denotes the full width at half maximum of various diffraction peaks, $\theta$ denotes Bragg's diffraction angle, and $\lambda$ shows the wavelength of target $\mathrm{Cu}-\mathrm{K} \alpha$.
The morphology and size of synthesized $\mathrm{nCeO}_{2}$ were observed using TEM studies. Figure $1(b-d)$ shows TEM, HRTEM, and selected area electron diffraction (SEAD) patterns, respectively. It is apparent from image (b) that almost all nanoparticles were spherical in shape, well dispersed, and uniform in size. Image (c) shows the well-resolved HR-TEM image that is comprised of organized lattice planes of $\mathrm{nCeO}_{2}$ with a cubic phase. The continuous and clearly visible lattice fringes are indicative of the crystallinity of $\mathrm{nCeO}_{2}$. Further, the interfringe distances (d) of $0.33 \mathrm{~nm}$ calculated using ImageJ software can be indexed to the (111) plane of cubic $\mathrm{nCeO}_{2}$ and strongly supported the XRD data. The inset of image (c) shows the particle size distribution graph which revealed the average size of $\mathrm{nCeO}_{2}$ to be $14.38 \pm 1.5 \mathrm{~nm}$. The SEAD pattern (image d) showed very bright spots of the rings which revealed the highly crystalline nature of $\mathrm{nCeO}_{2}$. The bright spots obtained on these rings were well indexed to (222), (220), (220), and (111) planes of cubic $\mathrm{nCeO}_{2}$ (JCPDS card 34-0394).

FTIR, Raman, and UV-visible spectroscopy (Fig. 2) techniques were employed to confirm the synthesis of $\mathrm{nCeO}_{2}$. FTIR spectrum analysis of $\mathrm{nCeO}_{2}$ (image a) shows some 


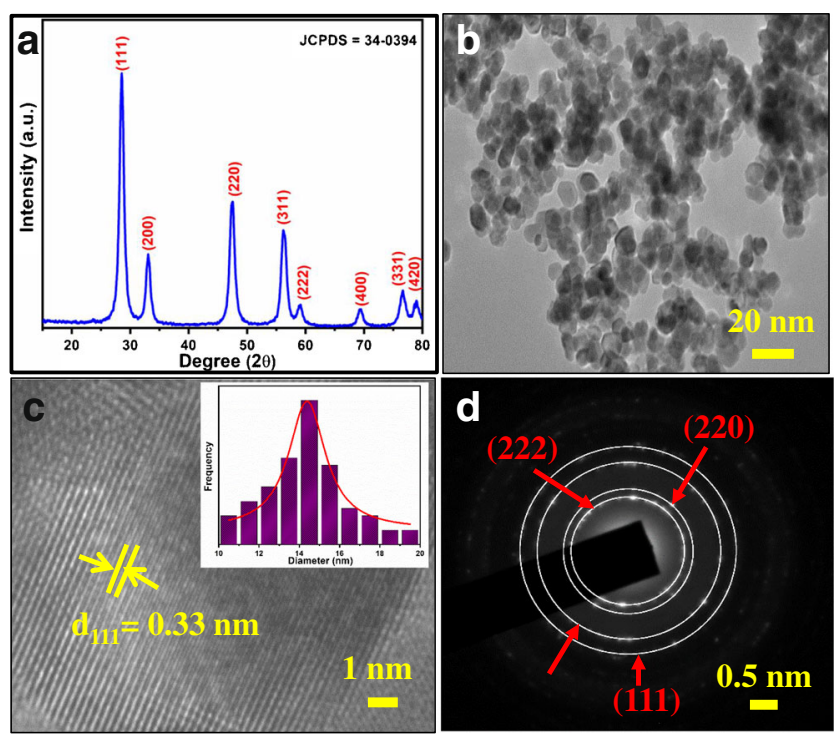

Fig. 1 (a) XRD spectrum of $\mathrm{nCeO}_{2}$, (b) TEM image, (c) HR-TEM image (inset shows size distribution of $\mathrm{nCeO}_{2}$ ), and (d) SEAD pattern for $\mathrm{nCeO}_{2}$, respectively

absorption bands in the region of 400 to $4000 \mathrm{~cm}^{-1}$. The band appeared at $660 \mathrm{~cm}^{-1}$ corresponds to Ce-O stretching vibration. Another stretching band observed at $1320 \mathrm{~cm}^{-1}$ revealed carbonate-like species $(\mathrm{O}-\mathrm{C}-\mathrm{O})$. The next band at $1635 \mathrm{~cm}^{-1}$ represents the "scissor" bending mode of molecular $\mathrm{H}_{2} \mathrm{O}(\mathrm{H}-$ $\mathrm{O}-\mathrm{H})$. Finally, a broad absorption band at $3410 \mathrm{~cm}^{-1}$ corresponds to $-\mathrm{OH}$ stretching vibration mode of (H-bonded) water molecules present due to physically absorbed $\mathrm{H}_{2} \mathrm{O}$ or surface -OH groups, respectively [32-34].

Figure 2 (b) shows the Raman spectrum of $\mathrm{nCeO}_{2}$ which exhibits one strong peak at $465 \mathrm{~cm}^{-1}$ and three other peaks of low intensity at 270,605 , and $1051 \mathrm{~cm}^{-1}$. The strong peak at $465 \mathrm{~cm}^{-1}$ belongs to the first-order Raman line and represents the characteristic peak of the cubic form of $\mathrm{nCeO}_{2}$ [33]. This peak may be attributed to triply degenerated Raman active optical phonon mode $\left(\mathrm{F}_{2 \mathrm{~g}}\right)$. The shoulder peak at $270 \mathrm{~cm}^{-1}$ is attributed to transverse optical (TO) doubly degenerate mode. Further, another two peaks at 605 and $1051 \mathrm{~cm}^{-1}$ belong to the second-order Raman line and were assigned to the longitudinal optical (LO) mode. Due to the presence of oxygen vacancies and the intrinsic defects in the $\mathrm{nCeO}_{2}$, a peak at $605 \mathrm{~cm}^{-1}$ was observed [35]. Also, the Raman analysis confirms the presence of a cubic fluorite structure with oxygen vacancies in the synthesized $\mathrm{nCeO}_{2}$.

Figure 2 (c) shows the UV/Vis absorption spectrum of synthesized $\mathrm{nCeO}_{2}$ (dispersed in D.I. water), recorded in the range of $250-600 \mathrm{~nm}$. The spectrum showed a strong absorption peak at $310 \mathrm{~nm}$ which is due to charge-transfer transitions from $\mathrm{O}$ atom through $2 p$ orbital to Ce atom in 4 f orbital $[33,36]$.

All these spectroscopic characterizations clearly supported the successful synthesis of $\mathrm{nCeO}_{2}$ without any impurity.

\section{Characterization of $\mathrm{nCeO} / 2$ C nanoplatform and $\mathrm{BSA} / \mathrm{anti}-25 \mathrm{VD}_{3} / \mathrm{nCeO}_{2} / \mathrm{CC}$ immunoelectrode}

Figure $3(\mathrm{a}-\mathrm{c})$ shows the morphology of $\mathrm{nCeO}_{2} / \mathrm{CC}$ nanoplatform and images $(\mathrm{d}-\mathrm{f})$ represent the conjugation of bioactive molecules (anti-25VD 3 and BSA) on the surface of $\mathrm{nCeO}_{2} / \mathrm{CC}$ nanoplatform, using the FE-SEM technique. Image (a) shows the FE-SEM image of $\mathrm{nCeO}_{2} / \mathrm{CC}$ nanoplatform where $\mathrm{CC}$ appears to be fibrous and deposition of $\mathrm{nCeO}_{2}$ onto this fibrous $\mathrm{CC}$ is also visible. However, image (b) shows the rough surface due to the uniform deposition of $\mathrm{nCeO}_{2}$, which provides a suitable platform for the immobilization of bioactive molecules. Figure 3 (c) shows the magnified view of $\mathrm{nCeO}_{2} /$ $\mathrm{CC}$ nanoplatform which suggests a globular morphology of uniformly deposited $\mathrm{nCeO}_{2}$ (spherical shaped) that are embedded onto the fibrous structure of CC. Therefore, good contact was established between $\mathrm{nCeO}_{2}$ and $\mathrm{CC}$ fibers.

Figure 3 (d, e, and f) shows the morphology of biomolecules conjugated $\mathrm{nCeO}_{2} / \mathrm{CC}$ nanoplatform. Image (d) reveals the increment in the roughness and appearance of some island like entities at the surface. This large increment in roughness and alteration in morphology is due to the conjugation of bioactive molecules onto the surface of the $\mathrm{nCeO}_{2} / \mathrm{CC}$ nanoplatform. Image (f) also shows the appearance of some $\mathrm{Y}$-shaped structures bound to $\mathrm{nCeO}_{2}$ due to the presence of anti-25VD 3 attachment. All these morphological changes revealed the successful conjugation of bioactive molecules and the fabrication of immunosensor ( $\mathrm{BSA} / \mathrm{anti}-\mathrm{VD}_{3} / \mathrm{nCeO}_{2} / \mathrm{CC}$ ).
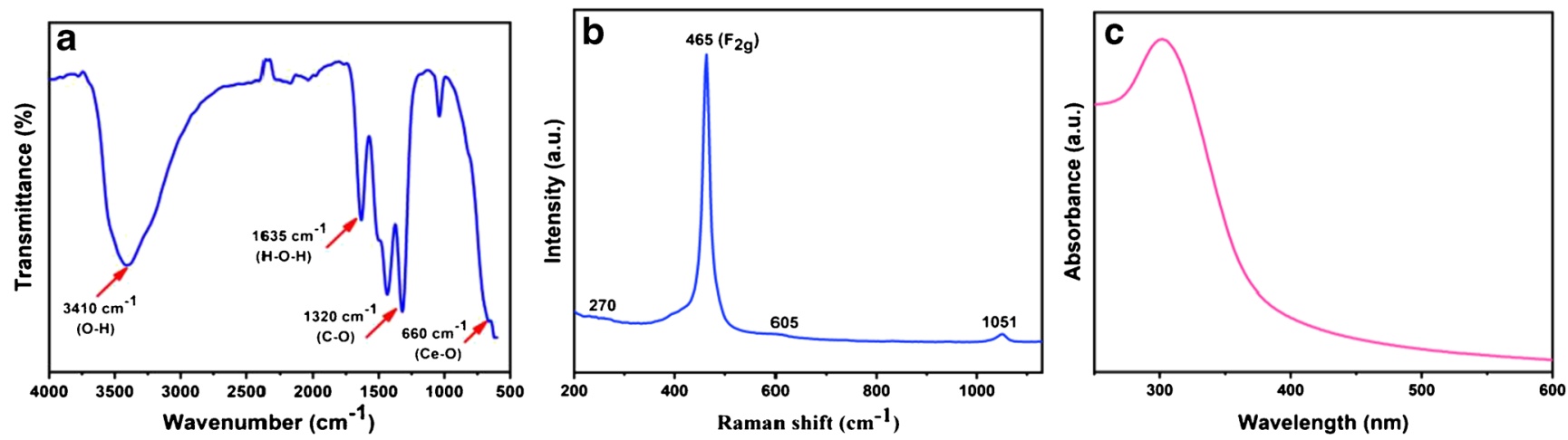

Fig. 2 (a) FTIR spectrum, (b) Raman spectrum, and (c) UV-visible spectrum of $\mathrm{nCeO}_{2}$ 

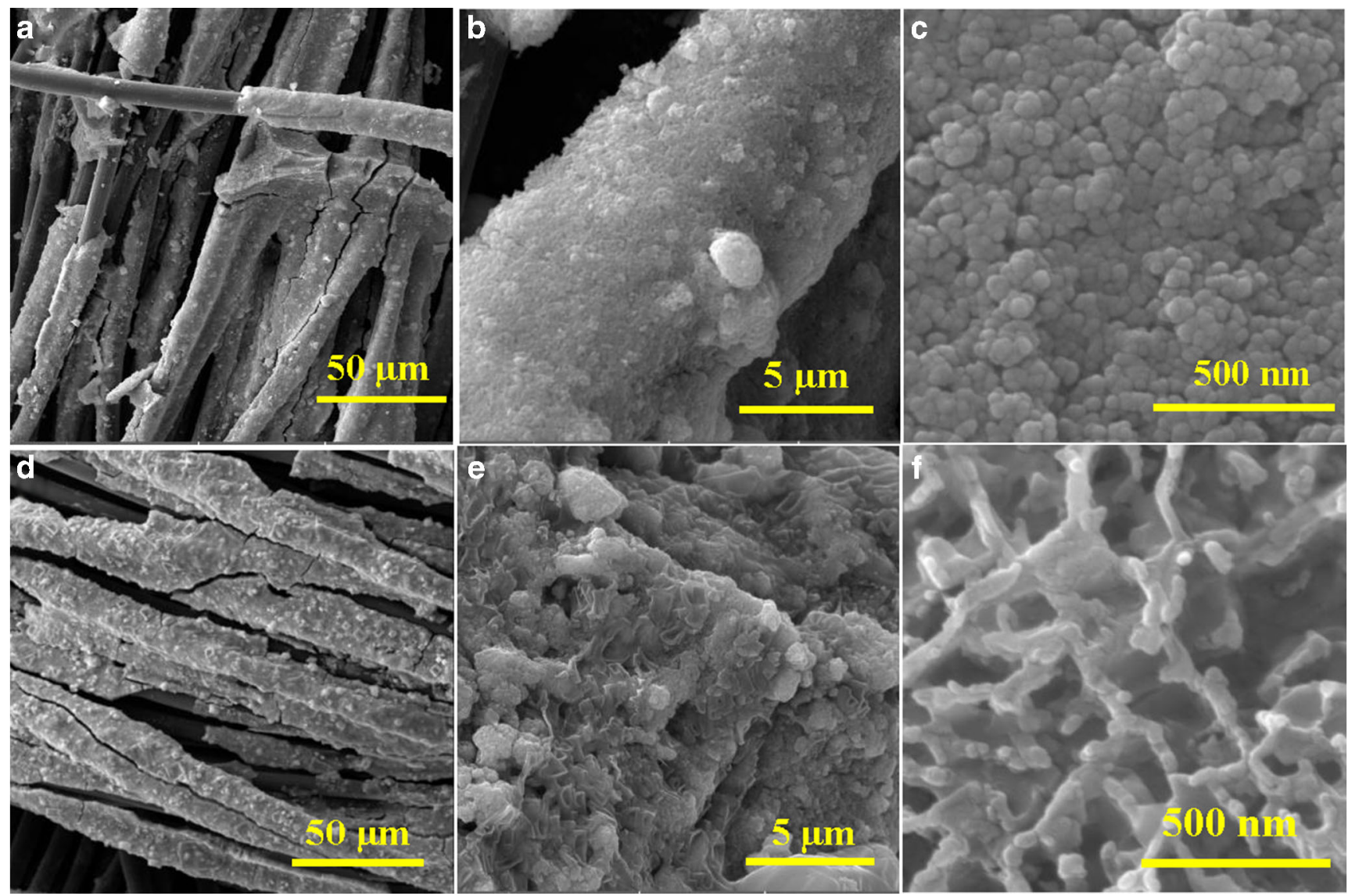

Fig. 3 (a, b, and c) FE-SEM images of $\mathrm{nCeO}_{2} / \mathrm{CC}$ nanoplatform, and (d, e, and f) $\mathrm{BSA} / \mathrm{anti}-\mathrm{VD}_{3} / \mathrm{nCeO}_{2} / \mathrm{CC}$ immunosensor at different scales, respectively

\section{Electrochemical studies}

The electrochemical techniques such as cyclic voltammetry (CV) and differential pulse voltammetry (DPV) measurements were carried out for characterization as well as for label-free detection of $25 \mathrm{VD}_{3}$. All measurements were done in PBS $(0.1 \mathrm{M}, \mathrm{pH} 7.0,0.9 \% \mathrm{NaCl})$ containing $5 \mathrm{mM}$ of $\left[\mathrm{Fe}(\mathrm{CN})_{6}\right]^{3}$ ${ }^{-/ 4-}$ as a redox probe using a conventional three-electrode system. The three-electrode system has the BSA/anti-25VD $/$ $\mathrm{nCeO}_{2} / \mathrm{CC}$ immunoelectrode $\left(0.25 \mathrm{~cm}^{2}\right)$ as a working electrode, an $\mathrm{Ag} / \mathrm{AgCl}$ reference electrode, and platinum wire $(0.25 \mathrm{~mm})$ as the counter electrode. $\mathrm{CV}$ was carried out at a scan rate of $50 \mathrm{mV} \mathrm{s}^{-1}$ in the potential range of $-0.6 \mathrm{~V}$ to $0.8 \mathrm{~V}$, while DPV was recorded in a potential range of $-0.6 \mathrm{~V}$ to $0.7 \mathrm{~V}$ with a pulse width of $50 \mathrm{~ms}$ and pulse height of $25 \mathrm{mV}$.

\section{pH study and electrochemical characterization studies}

The influence of different $\mathrm{pH}$ of PBS ranging from 6.0 to 8.0 was evaluated to analyze the behavior of antibodies [37] present on the immunosensor (BSA/anti- $25 \mathrm{VD}_{3} / \mathrm{nCeO}_{2} / \mathrm{CC}$ ) and the highest peak current was found at $\mathrm{pH} 7.0$ (Figure S2).

Figure 4 (a) shows the $\mathrm{CV}$ of (i) bare ITO, (ii) $\mathrm{CC}$, (iii) $\mathrm{nCeO} / \mathrm{CC}$, (iv) anti- $25 \mathrm{VD}_{3} / \mathrm{nCeO}_{2} / \mathrm{CC}$, and (v) $\mathrm{BSA} /$ anti-
$25 \mathrm{VD}_{3} / \mathrm{nCeO}_{2} / \mathrm{CC}$ immunosensor in PBS $(\mathrm{pH} 7.0)$ containing $\left[\mathrm{Fe}(\mathrm{CN})_{6}\right]^{3-/ 4-}$ as a redox probe. $\mathrm{CC}$ exhibited oxidation and reduction in peak current much higher $(1118.6 \mu \mathrm{A})$ than that of ITO $(367 \mu \mathrm{A})$ which is a typical characteristic of CC. The higher current value obtained is due to the good electrical conductivity, larger specific surface area and a higher carbonization degree of $\mathrm{CC}$. After the inclusion of $\mathrm{nCeO}_{2}$, the oxidation peak current is enhanced to $1855.6 \mu \mathrm{A}$ (curve iii; $\mathrm{nCeO}_{2} / \mathrm{CC}$ nanoplatforms). This confirms the deposition of $\mathrm{nCeO}_{2}$ onto $\mathrm{CC}$ and increases the overall electroactive surface of the nanoplatforms, resulting in acceleration of electron transport between the redox probe and the platform surface [38]. The magnitude of the current was decreased to $1480.7 \mu \mathrm{A}$ (curve iv) after the conjugation of anti- $25 \mathrm{VD}_{3}$ and to $1342.6 \mu \mathrm{A}$ (curve v) after BSA immobilization. This decrease could be attributed to the insulating effect of bioactive molecules (anti-25VD 3 and BSA) that obstructed the diffusion of the electrons generated from the redox probe to the platform surface [39], which confirmed the sequential modification. These $\mathrm{CV}$ results were found in good agreement with DPV results (Fig. 4 (b)). Moreover, electrochemical impednce spectroscopy (EIS) study has been performed which further support sequential modification of electrodes (Fig. S3). 
Besides this, the evaluation of the scan rate effect from 10 to $100 \mathrm{mV} \mathrm{s}^{-1}$ has been done to explain the electrochemical activity of fabricated $\mathrm{nCeO}_{2} / \mathrm{CC}$ nanoplatform and $\mathrm{BSA} /$ anti$25 \mathrm{VD}_{3} / \mathrm{nCeO}_{2} / \mathrm{CC}$ immunosensor (Figure $\mathrm{S} 4$ ). The variation of anodic and cathodic peak currents $\left(I_{\mathrm{pa}} / I_{\mathrm{pc}}\right)$ as a function of the square root of the scan rates $(\sqrt{ })$ showed a straight line and the value of $I_{\mathrm{pa}} / I_{\mathrm{pc}}$ was found as $\sim 1$ for BSA/anti-25VD $3 /$ $\mathrm{nCeO}_{2} / \mathrm{CC}$ immunoelectrode revealing the transfer to be quasi-reversible kinetics. Also, for both platforms, the peak current $I_{\mathrm{pa}}$ (anodic) and $I_{\mathrm{pc}}$ (cathodic) were increased linearly with $\sqrt{ }$, indicating a diffusion-controlled process between the immunosensor surface and the redox probe.

\section{Analytical performance of the immunosensor}

The response of the fabricated immunosensor (BSA/anti$25 \mathrm{VD}_{3} / \mathrm{nCeO}_{2} / \mathrm{CC}$ ) was studied as a function of $25 \mathrm{VD}_{3}$. The optimization of incubation time for the interaction of $25 \mathrm{VD}_{3}$ ( $1 \mathrm{ng} \mathrm{mL}{ }^{-1}$ ) with the immunosensor platform was conducted at an interval of $3 \mathrm{~min}$ (Fig. 5 (a)) up to $15 \mathrm{~min}$. The peak current was decreased from 0 to $9 \mathrm{~min}$ and then became almost constant from 10 to $15 \mathrm{~min}$. Therefore, $15 \mathrm{~min}$ was set as an optimized incubation time for the response studies.

The response of the developed immunosensor towards detection of $25 \mathrm{VD}_{3}$ from 1 to $200 \mathrm{ng} \mathrm{mL}{ }^{-1}$ was measured through the DPV technique. The decreasing trend in peak current was found after the addition of each $25 \mathrm{VD}_{3}$ concentration (Fig. 5 (b)) and became constant at $180 \mathrm{ng} \mathrm{mL}^{-1}$. The decreasing trend in the peak current was attributed to the interaction of $25 \mathrm{VD}_{3}$ with anti-25VD 3 that led to the formation of an electrically insulating complex. This complex obstructed the transfer of electrons between the redox probe and immunosensor. A $200 \mathrm{ng} \mathrm{mL}{ }^{-1}$ of $25 \mathrm{VD}_{3}$ concentration was found enough for saturation of available anti-25VD 3 present on the nanobioplatform surface. Here, $1 \mathrm{ng} \mathrm{mL}^{-1}$ was the

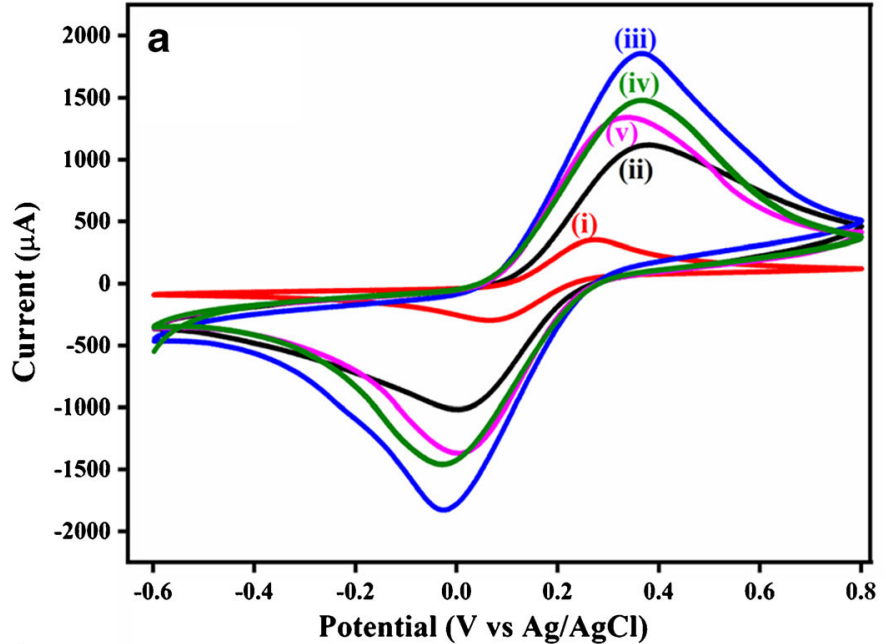

lowest concentration of $25 \mathrm{VD}_{3}$ that could be detected with the present immunosensor.

The mechanism behind the decreasing trend in the peak current was attributed to the charge transfer factor and shift in the Fermi level between $\mathrm{nCeO}_{2}$ and bioactive molecules. The size of $25 \mathrm{VD}_{3}$ is bulky in comparison to $\mathrm{nCeO}_{2}(\mathrm{~nm})$, therefore preventing the flow of electrons to immunosensor from the redox probe. The chemical bond formation between the bioactive molecules (anti-25VD $3, \mathrm{BSA}$, and $25 \mathrm{VD}_{3}$ ) at the semiconductor surface $\left(\mathrm{nCeO}_{2}\right)$ is analyzed that showed the presence of two factors contributing to adsorption energy: one is bond creation and the second is charge transfer. The charge transfer factor decides the direction of the Fermi level shift in the bandgap region either from semiconductor to bioreceptors or vice versa. Electron transfer from the $25 \mathrm{VD}_{3}$ molecule will take place to the conduction band of the working electrode followed by the transition to its valence band leading to electron-hole $(\mathrm{e}-\mathrm{h})$ pair recombination. As a result, the hole concentration in the valence band will be reduced; consequently, the extrinsic Fermi level will be shifted away from the valence band, leading to downward band bending and a decrease in the current trend [40].

Figure 5 (c) shows the calibration curve between the change in peak current obtained through the DPV study and the $25 \mathrm{VD}_{3}$ concentrations. The calibration curve clearly revealed a linear and inverse relationship between current values and $25 \mathrm{VD}_{3}$ concentrations. The experiments were repeated thrice and the error bar shows the standard deviation. Sensitivity was estimated from the formula: calibration curve slope/surface area of immunosensor $\left(0.25 \mathrm{~cm}^{2}\right)$ and found to be $2.08 \mu \mathrm{A} \mathrm{ng}^{-1} \mathrm{~mL} \mathrm{~cm}^{-2}$ with $R^{2}$ of 0.989 . The immunosensor lower detection limit and the linear range were observed as $4.63 \mathrm{ng} \mathrm{mL}^{-1}$ and $1-160 \mathrm{ng} \mathrm{mL}^{-1}$, respectively. These obtained biosensing parameters of are much better than the previously reported biosensors (Table 1). All the

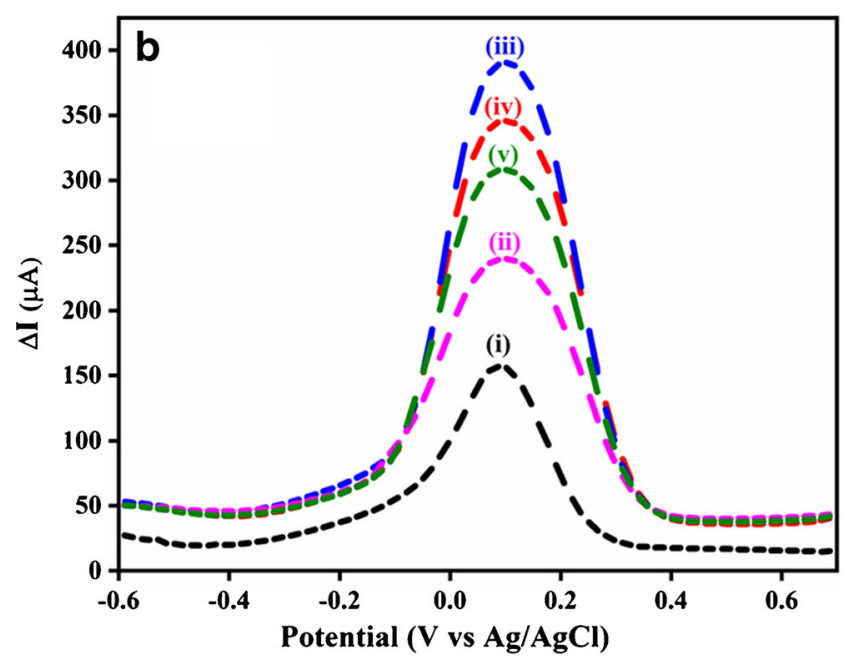

Fig. 4 (a) $\mathrm{CV}$ and (b) DPV studies of (i) ITO, (ii) $\mathrm{CC}$, (iii) $\mathrm{nCeO}_{2} / \mathrm{CC}$, (iv) anti- $25 \mathrm{VD}_{3} / \mathrm{nCeO}_{2} / \mathrm{CC}$, and (v) $\mathrm{BSA} /$ anti- $25 \mathrm{VD}_{3} / \mathrm{nCeO}_{2} / \mathrm{CC}$ immunosensor, respectively 
measurements were performed three times to check the repeatability and reproducibility of the developed immunosensor.

The linear plot between peak current and $25 \mathrm{VD}_{3}$ concentration provided the equation:

$I_{p}=0.52$ conc. $\left(\mathrm{ng} \mathrm{mL}^{-1}\right)+292.18 \mu A, R^{2}=0.989$

\section{Specificity, reproducibility, and stability}

Specificity is an important and vital parameter for the majority of the biosensor as the nonspecific bindings can hinder and mislead the results of $25 \mathrm{VD}_{3}$ detection. Thus, the specificity of the fabricated immunosensor was evaluated by introducing some interfering species that are present in serum samples such as glucose (GLU), ascorbic acid (AA), urea, uric acid (UA), and oxalic acid (OA) and keeping a $25 \mathrm{VD}_{3}$ concentration of $100 \mathrm{ng} \mathrm{mL}{ }^{-1}$ onto BSA/anti- $25 \mathrm{VD}_{3} / \mathrm{nCeO}_{2} / \mathrm{CC}$ immunosensor. The evaluation has been shown in terms of a bar graph (Fig. 6 (a)). Results revealed an excellent specificity of immunosensor towards detection of $25 \mathrm{VD}_{3}$. Biosensors are specific in nature rather than selective as the development of a biosensor is based on the utilization of bioactive molecules (antibody, enzyme, tissue, etc.) which are specific to their respective analyte. The present immunosensor utilized antibodies (anti-25VD 3 ) specific to the target analyte $\left(25 \mathrm{VD}_{3}\right)$ and hence detect $25 \mathrm{VD}_{3}$ significantly and did not respond to other interfering species. However, the fabricated platform $\mathrm{nCeO}_{2} / \mathrm{CC}$ can be applied for the detection of various other diagnostic biomarkers (vitamins, cancer, food toxins, antibiotics, and pesticides, etc.) by simply changing the analytespecific bioactive molecules.

Six different nanobioplatforms (BSA/anti- $25 \mathrm{VD}_{3} / \mathrm{nCeO}_{2} /$ $\mathrm{CC}$ ) were prepared under similar conditions and used individually for reproducibility studies (Fig. 6 (b)). The peak value of all independent electrodes remained nearly the same and the value of RSD was calculated to be $4.62 \%$, suggesting high precision and acceptable range. This showed that the
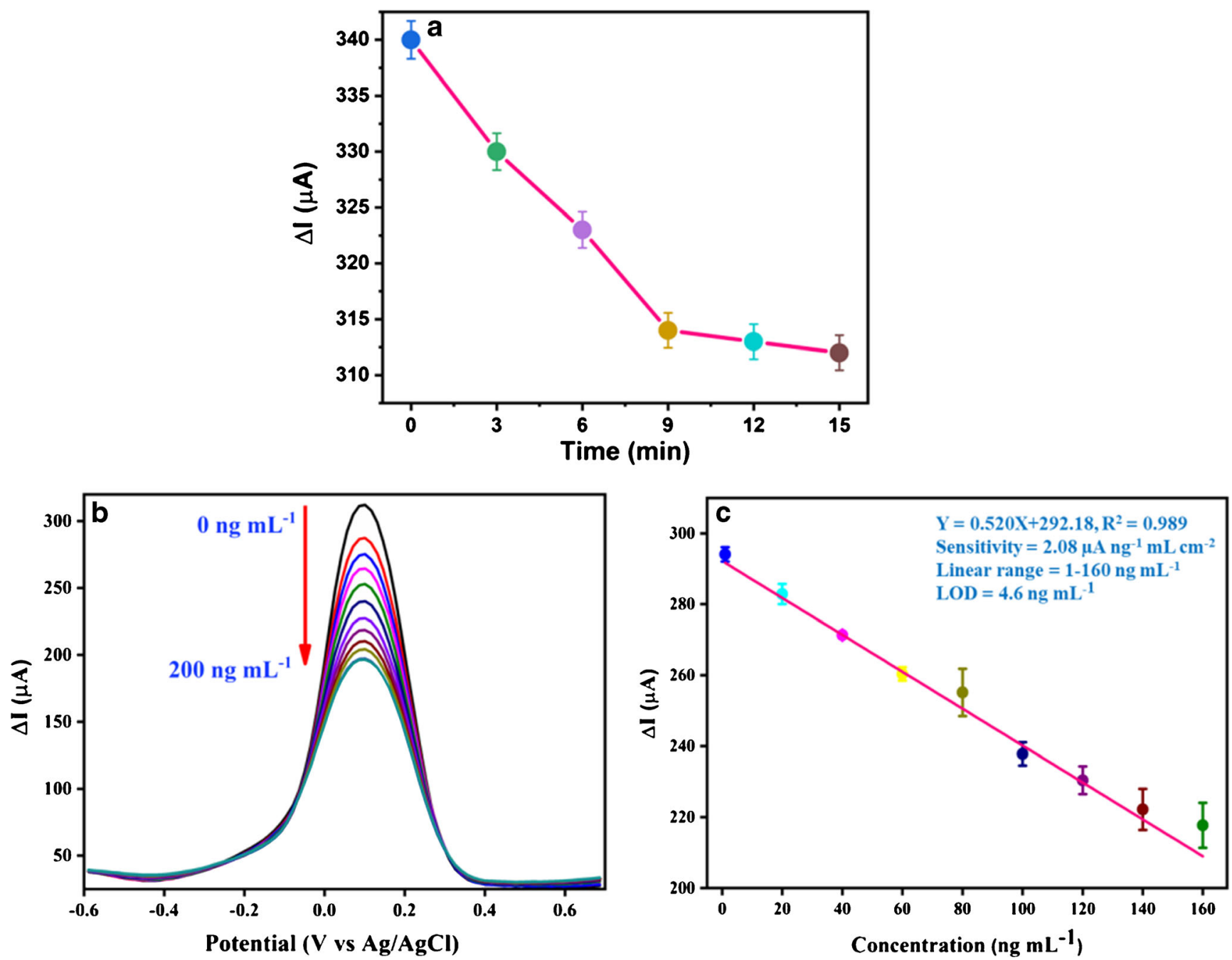

Fig. 5 (a) Incubation time study, (b) analytic performance of $\mathrm{BSA} / \mathrm{anti}-25 \mathrm{VD}_{3} / \mathrm{nCeO}_{2} / \mathrm{CC}$ immunosensor in term of $\mathrm{DPV}$ as a function of $25 \mathrm{VD} 3$ concentration (1-200 ng mL ${ }^{-1}$ ), and (c) calibration plot of peak current and $25 \mathrm{VD}_{3}$ concentrations 

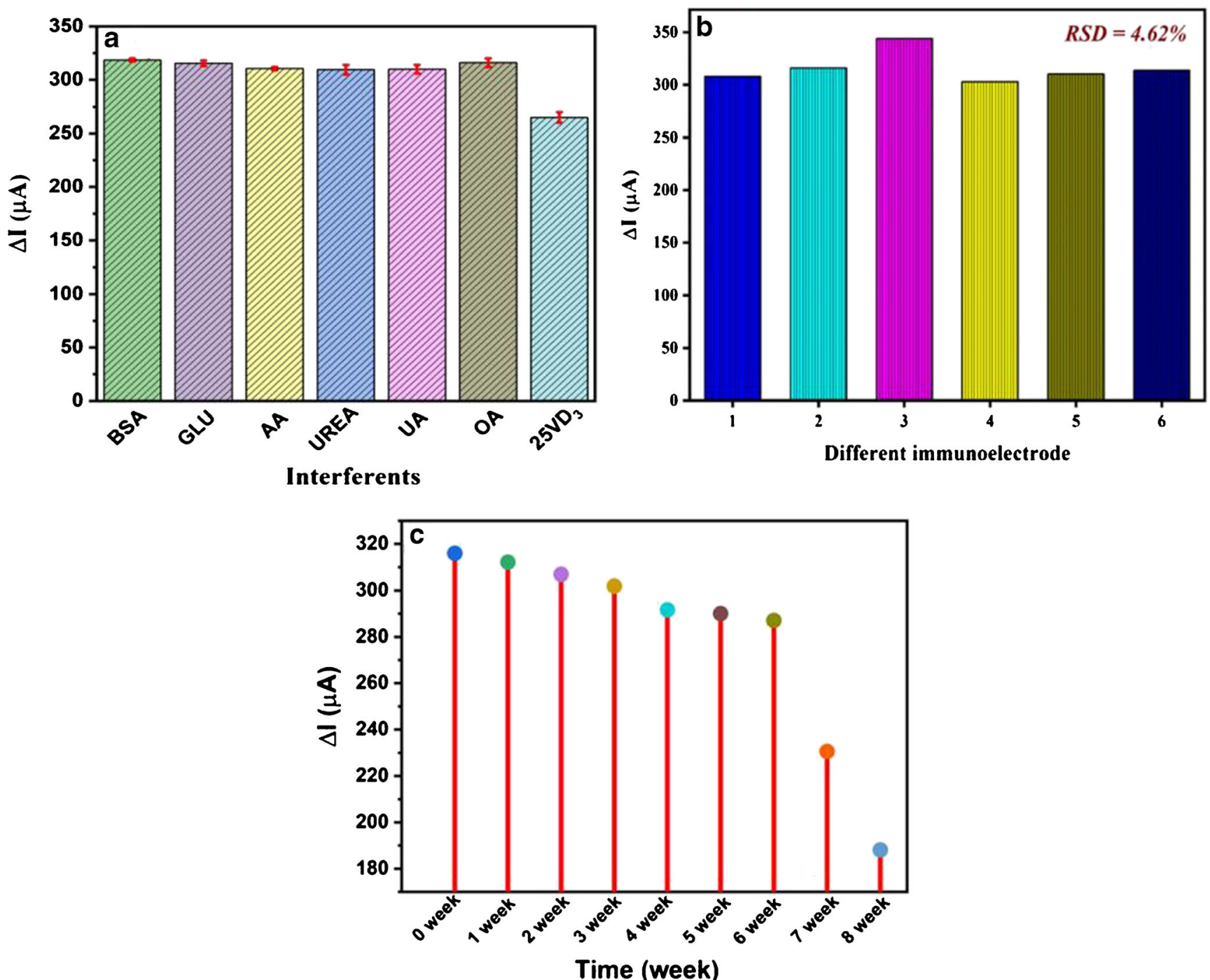

Fig. 6 (a) Specificity, (b) reproducibility, and (c) stability of fabricated BSA/anti- $25 \mathrm{VD}_{3} / \mathrm{nCeO}_{2} / \mathrm{CC}$ immunosensor

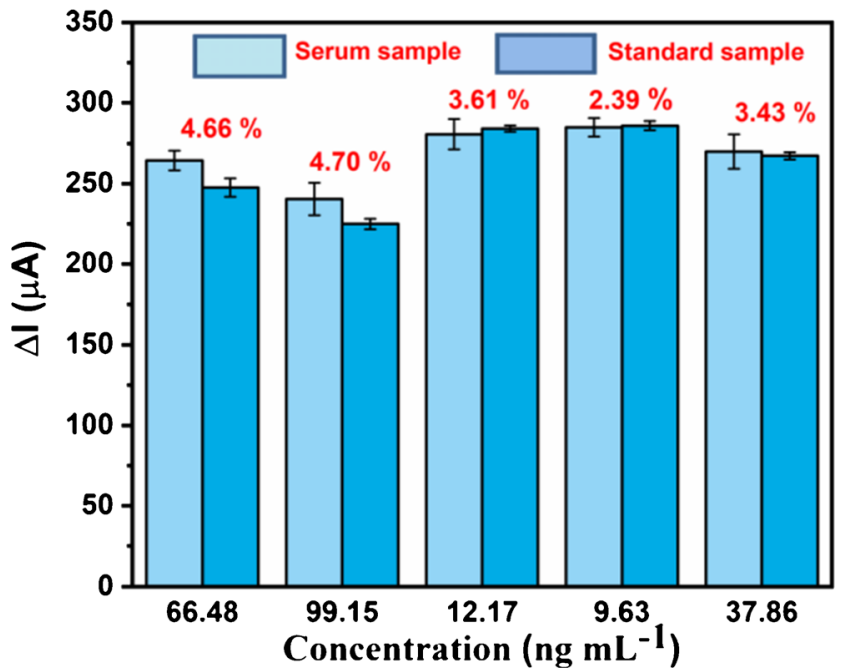

Fig. 7 Serum sample analysis onto fabricated $\mathrm{BSA} / \mathrm{anti}-25 \mathrm{VD}_{3} / \mathrm{nCeO}_{2} /$ $\mathrm{CC}$ immunosensor fabricated immunosensor represented good reproducibility apart from specificity.

Moreover, the stability of fabricated immunosensor is a key factor that must be observed over a period of time and it was determined by observing the value of peak current after a regular interval of 1 week for 8 weeks. As shown in Fig. 6 (c), the value of peak current showed a certain degree of decrease which was not significant for up to 6 weeks. The obtained results revealed excellent stability of immunosensor for about 45 days. After 6 weeks, a notable decrease in peak current was observed which was almost $30 \%$ of the initial peak current value. The decrease became almost $50 \%$ after 8 weeks of the time.

Generally, the stability of a biosensor is influenced by degradation of the bioactive molecules over a period of time [41, 42]. Hence, in the present immunosensor, the reason of performance deterioration in the stability is due to the activity loss of the antibodies (anti-25VD 3 ). 


\section{ELISA and real sample analysis}

The serum samples were obtained from U Healthcare \& Diagnostic Laboratory, New Delhi (India). The quantification of serum samples was done with ELISA using a kit having an antigen $\left(25 \mathrm{VD}_{3}\right)$ precoated 96 -well plate in triplicate. ELISA was performed according to manual instructions and absorbance was recorded using an ELISA plate reader $(450 \mathrm{~nm})$ to get the quantified concentration of serum samples. The obtained concentrations of $25 \mathrm{VD}_{3}$ in serum samples were 66.48 , $99.15,12.17,9.63$, and $37.68 \mathrm{ng} \mathrm{mL}^{-1}$ as shown in the second column of Table S3. After quantification, serum samples were incubated for $15 \mathrm{~min}$ and electrochemical analysis (DPV response) was observed onto the fabricated immunosensor to check its performance towards serum samples. It was found that a reasonable correlation existed between the magnitude of the DPV current response of the fabricated immunosensor incubated with the serum samples $\left(25 \mathrm{VD}_{3}\right.$ determined by ELISA) and with the standard $25 \mathrm{VD}_{3}$ concentrations (Fig. 7). The observed results exhibited \% RSD values less than $10 \%$ indicating high accuracy of fabricated immunosensor. A tabular representation for the serum sample analysis is also summarized in Table S3.

\section{Conclusion}

Here, a novel electrochemical immunosensor based on $\mathrm{CC}$ for detection of $25 \mathrm{VD}_{3}$ was proposed. $\mathrm{nCeO}_{2}$ was synthesized through a simple bottom-up approach and further utilized for immunosensor development. EPD was applied for anchoring $n \mathrm{CeO}_{2}$ onto $\mathrm{CC}$ to get a highly conductive $\mathrm{nCeO}_{2} / \mathrm{CC}$ nanoplatform. $\mathrm{CC}$ confers higher conductivity and provides a large surface area than other substrates (ITO, GCE, etc.) and the inclusion of $\mathrm{nCeO}_{2}$ onto $\mathrm{CC}$ facilitates faster electron transfer. The developed immunosensor showed excellent biosensing parameters along with high specificity, reproducibility, and stability. The proposed immunosensor was then applied to detect $25 \mathrm{VD}_{3}$ levels in human serum samples. The immunosensor showed promising results and faster detection (15 min) compared to traditional methods of ELISA with acceptable relative error. This study proves the combination of $\mathrm{CC}$ and $\mathrm{nCeO}_{2}$ as a promising platform for biosensor development because of their remarkable properties. It is to be noted that CC-based low-cost, disposable, and highly electroactive-based nanobioplatform added advantages towards the production of wearable sensors, developing labon-biochip and POC diagnosis platforms. However, in the present work, drop cast was not successful to fabricate the nanoplatform as $\mathrm{CC}$ is permeable. Hence, to overcome this, EPD was applied for anchoring $\mathrm{nCeO}_{2}$ onto $\mathrm{CC}$ to get a tightly bound and highly conductive $\mathrm{nCeO}_{2} / \mathrm{CC}$ nanoplatform that can adhere the bioactive molecules well onto its surface to develop immunosensor. Further, we believe that the developed platform can be applied for the detection of different diagnostic biomarkers just by replacing the bioreceptors specific to target analyte.

Supplementary Information The online version contains supplementary material available at https://doi.org/10.1007/s00604-021-04751-y.

Acknowledgments The authors thank AIRF, JNU, for the characterization facilities of TEM, and FESEM. We sincerely thank to Kashyap Dave at SCNS, JNU, for his guidance and constant help towards CC.

Funding This work received financial supports from the Government of India through Indo-Russia (DBT/IC-2/Indo-Russia/2017-19/02), DST Purse. Deepika Chauhan received funding from UGC through the UGC-SRF scheme.

\section{Compliance with ethical standards}

Conflict of interest The authors declare no competing interests.

\section{References}

1. Adela R, Borkar RM, Bhandi MM, Vishwakarma G, Reddy PNC, Srinivas R, Banerjee SK (2016) Lower vitamin D metabolites levels were associated with increased coronary artery diseases in type 2 diabetes patients in India. Scientific reports 6(1):1-13

2. Dalgard, Christine, Maria ska alum Petersen, Pal Weihe, and Philippe Grandjean. "Vitamin D status in relation to glucose metabolism and type 2 diabetes in septuagenarians." Diabetes Care 34, no. 6 (2011): 1284-1288

3. Rezayi M, Ghayour-Mobarhan M, Sany SBT, Fani M, Avan A, Pasdar Z, Ferns GA, Abouzari-Lotf E, Amiri IS (2018) A comparison of analytical methods for measuring concentrations of 25hydroxy vitamin D in biological samples. Anal Methods 10(47): 5599-5612

4. Chauhan D, Solanki PR (2019) Hydrophilic and insoluble electrospun cellulose acetate fiber-based biosensing platform for 25-hydroxy vitamin- $\mathrm{D}_{3}$ detection. ACS Applied Polymer Materials 1(7):1613-1623

5. Pilz S, Zittermann A, Trummer C, Theiler-Schwetz V, Lerchbaum E, Keppel MH, Grübler MR, März W, Pandis M (2019) Vitamin D testing and treatment: a narrative review of current evidence. Endocrine connections 8(2):R27-R43

6. Yin S, Yang Y, Wu L, Li Y, Sun C (2019) Recent advances in sample preparation and analysis methods for vitamin D and its analogues in different matrices. TrAC Trends Anal Chem 110: 204-220

7. Sakamoto S, Putalun W, Vimolmangkang S, Phoolcharoen W, Shoyama Y, Tanaka H, Morimoto S (2018) Enzyme-linked immunosorbent assay for the quantitative/qualitative analysis of plant secondary metabolites. J Nat Med 72(1):32-42

8. Kaushik AK, Dhau JS, Gohel H, Mishra YK, Kateb B, Kim N-Y, Goswami DY (2020) Electrochemical SARS-CoV-2 sensing at point-of-care and artificial intelligence for intelligent COVID-19 management. ACS Applied Bio Materials 3(11):7306-7325

9. Kaushik, Ajeet, and Mubarak A. Mujawar. "Point of care sensing devices: better care for everyone." (2018): 4303

10. Kaushik A (2019) Biomedical nanotechnology related grand challenges and perspectives. Front Nanotechnol 1:1 
11. Chauhan D, Gupta PK, Solanki PR (2018) Electrochemical immunosensor based on magnetite nanoparticles incorporated electrospun polyacrylonitrile nanofibers for vitamin- $\mathrm{D}_{3}$ detection. Mater Sci Eng C 93:145-156

12. Chauhan D, Kumar R, Panda AK, Solanki PR (2019) An efficient electrochemical biosensor for vitamin- $\mathrm{D}_{3}$ detection based on aspartic acid functionalized gadolinium oxide nanorods. Journal of Materials Research and Technology 8(6):5490-5503

13. Sarkar T, Bohidar HB, Solanki PR (2018) Carbon dots-modified chitosan based electrochemical biosensing platform for detection of vitamin D. Int J Biol Macromol 109:687-697

14. Ozbakir HF, Sambade D, Majumdar S, Linday L, Banta S, West $\mathrm{AC}$ (2015) Detection of 25-hydroxyvitamin $\mathrm{D}_{3}$ with an enzyme modified electrode. J. Biosens Bioelectron 7:193

15. Carlucci, Luciano, Gabriele Favero, Cristina Tortolini, Massimo Di Fusco, Elisabetta Romagnoli, Salvatore Minisola, and Franco Mazzei. "Several approaches for vitamin D determination by surface plasmon resonance and electrochemical affinity biosensors." Biosens Bioelectron 40, no. 1 (2013): 350-355

16. Kaur A, Kapoor S, Bharti A, Rana S (2020) Ganga Ram Chaudhary, and Nirmal Prabhakar. Gold-platinum bimetallic nanoparticles coated 3-(aminopropyl) triethoxysilane (APTES) based electrochemical immunosensor for vitamin D estimation. Journal of Electroanalytical Chemistry 873:114400

17. Ansari AA, Solanki PR, Malhotra BD (2009) Hydrogen peroxide sensor based on horseradish peroxidase immobilized nanostructured cerium oxide film. Journal of Biotechnology 142(2):179-184

18. Pachauri N, Dave K, Dinda A, Solanki PR (2018) Cubic $\mathrm{CeO}_{2}$ implanted reduced graphene oxide-based highly sensitive biosensor for non-invasive oral cancer biomarker detection. J Mater Chem B 6(19):3000-3012

19. Charbgoo F, Ramezani M, Darroudi M (2017) Bio-sensing applications of cerium oxide nanoparticles: advantages and disadvantages. Biosens Bioelectron 96:33-43

20. Nesakumar N, Sethuraman S, Krishnan UM, Rayappan JBB (2013) Fabrication of lactate biosensor based on lactate dehydrogenase immobilized on cerium oxide nanoparticles. J Colloid Interface Sci 410:158-164

21. Jianrong C, Yuqing M, He N, Wu X, Sijiao L (2004) Nanotechnology and biosensors. Biotechnol Adv 22(7):505-518

22. Zhu C, Yang G, He L, Dan D, Lin Y (2015) Electrochemical sensors and biosensors based on nanomaterials and nanostructures. Anal Chem 87(1):230-249

23. Cincy J, Milja TE, Prathish KP (2017) Fabrication of a flexible carbon cloth based solid contact iodide selective electrode. Anal Methods 9(20):2947-2956

24. Ye D, Yu Y, Tang J, Lin L, Yue W (2016) Electrochemical activation of carbon cloth in aqueous inorganic salt solution for superior capacitive performance. Nanoscale 8(19):10406-10414

25. Chen T, Li X, Qiu C, Zhu W, Ma H, Chen S, Meng O (2014) Electrochemical sensing of glucose by carbon cloth-supported $\mathrm{Co}_{3} \mathrm{O}_{4} / \mathrm{PbO}_{2}$ core-shell nanorod arrays. Biosens Bioelectron 53: 200-206

26. Mahesh KPO, Shown I, Chen L-C, Chen K-H, Tai Y (2018) Flexible sensor for dopamine detection fabricated by the direct growth of $\alpha-\mathrm{Fe} 2 \mathrm{O} 3$ nanoparticles on carbon cloth. Appl Surf Sci 427:387-395

27. Chen H-I, Chang H-Y (2004) Homogeneous precipitation of cerium dioxide nanoparticles in alcohol/water mixed solvents. Colloids Surf A Physicochem Eng Asp 242(1-3):61-69

28. Chen HI, Chang HY (2005) Synthesis of nanocrystalline cerium oxide particles by the precipitation method. Ceram Int 31:795-802
29. Besra L, Liu M (2007) A review on fundamentals and applications of electrophoretic deposition (EPD). Prog Mater Sci 52(1):1-61

30. Liu Y, Ren L, Zhang Z, Qi X, Li H, Zhong J (2016) 3D binder-free $\mathrm{MoSe}_{2}$ nanosheets/carbon cloth electrodes for efficient and stable hydrogen evolution prepared by simple electrophoresis deposition strategy. Sci Rep 6(1):1-9

31. Gao W, Zhang Z, Li J, Ma Y, Yongquan Q (2015) Surface engineering on $\mathrm{CeO}_{2}$ nanorods by chemical redox etching and their enhanced catalytic activity for CO oxidation. Nanoscale 7(27): 11686-11691

32. Krishnamoorthy, Karthikeyan, Murugan Veerapandian, Ling-He Zhang, Kyusik Yun, and Sang Jae Kim. "Surface chemistry of cerium oxide nanocubes: toxicity against pathogenic bacteria and their mechanistic study." J Ind Eng Chem 20, no. 5 (2014): 35133517

33. Liu YH, Zuo JC, Ren XF, Yong L (2014) Synthesis and character of cerium oxide $\left(\mathrm{CeO}_{2}\right)$ nanoparticles by the precipitation method. Metalurgija 53(4):463-465

34. Zamiri R, Ahangar HA, Kaushal A, Zakaria A, Zamiri G, Tobaldi D, Ferreira JMF (2015) Dielectrical properties of $\mathrm{CeO}_{2}$ nanoparticles at different temperatures. PLoS One 10(4):e0122989

35. Dhiman TK, Lakshmi GBVS, Roychoudhury A, Jha SK, Solanki PR (2019) Ceria-Nanoparticles-Based Microfluidic Nanobiochip Electrochemical Sensor for the Detection of Ochratoxin-A. ChemistrySelect 4(17):4867-4873

36. Jayakumar G, Albert Irudayaraj A, Dhayal Raj A (2017) Particle size effect on the properties of cerium oxide $\left(\mathrm{CeO}_{2}\right)$ nanoparticles synthesized by hydrothermal method. Mechanics, Materials Science \& Engineering Journal 9(1)

37. Umar A, Rahman MM, Al-Hajry A, Hahn YB (2009) Highlysensitive cholesterol biosensor based on well-crystallized flowershaped $\mathrm{ZnO}$ nanostructures. Talanta 78(1):284-289

38. Solanki PR, Dhand C, Kaushik A, Ansari AA, Sood KN, Malhotra BD (2009) Nanostructured cerium oxide film for triglyceride sensor. Sensors and Actuators B: Chemical 141(2):551-556

39. Garg M, Chatterjee M, Sharma AL, Singh S (2020) Label-free approach for electrochemical ferritin sensing using biosurfactant stabilized tungsten disulfide quantum dots. Biosens Bioelectron 151:111979

40. Gulati P, Kaur P, Rajam MV, Srivastava T, Mishra P, Islam SS (2019) Vertically aligned multi-walled carbon nanotubes based flexible immunosensor for extreme low level detection of multidrug resistant leukemia cells. Sensors and Actuators B: Chemical 301: 127047

41. Zhang Y, Wei Q (2016) The role of nanomaterials in electroanalytical biosensors: a mini review. J Electroanal Chem 781:401-409

42. Bhakta SA, Evans E, Benavidez TE, Garcia CD (2015) Protein adsorption onto nanomaterials for the development of biosensors and analytical devices: a review. Anal Chim Acta 872:7-25

43. Weblink 1: https://www.healthline.com/health-news/new-studyfound-80-percent-of-covid-19-patients-were-vitamin-d-deficient

44. Weblink 2: https://www.ncbi.nlm.nih.gov/pmc/articles/ PMC7385774/

45. Weblink 3: https://jamanetwork.com/journals/jama/fullarticle/ 2775003

46. Weblink 4: https://www.nutraingredients.com/Article/2020/08/19/ Study-adds-weight-to-link-between-COVID-19-and-vitamin-D

Publisher's note Springer Nature remains neutral with regard to jurisdictional claims in published maps and institutional affiliations. 